\title{
Effects of Acute Pump Speed Changes on Cerebral Hemodynamics in Patients With an Implantable Continuous-Flow Left Ventricular Assist Devices
}

\author{
Miroslav KONARIK ${ }^{1,2}$, Marek SRAMKO ${ }^{3,4}$, Zora DORAZILOVA ${ }^{3}$, Martin BLAHA ${ }^{3}$, \\ Ivan NETUKA $^{1,5}$, Peter IVAK ${ }^{1,6,7}$, Jiri MALY ${ }^{1}$, Ondrej SZARSZOI ${ }^{1,8}$
}

${ }^{1}$ Dept. of Cardiac Surgery, Institute for Clinical and Experimental Medicine, Prague, Czech Republic, ${ }^{2}$ Dept. of Physiology, First Faculty of Medicine, Charles University, Prague, Czech Republic, ${ }^{3}$ Dept. of Cardiology, Institute for Clinical and Experimental Medicine, Prague, Czech Republic, ${ }^{4} 2^{\text {nd }}$ Dept. of Internal Medicine, First Faculty of Medicine, Charles University, Prague, Czech Republic, ${ }^{5}$ Second Department of Surgery, Dept. of Cardiovascular Surgery, First Faculty of Medicine, Charles University in Prague, Prague, Czech Republic, ${ }^{6}$ Dept. of Physiology, Third Faculty of Medicine, Charles University, Prague, Czech Republic, ${ }^{7}$ Second Dept. of Surgery, Dept. of Cardiovascular Surgery, First Faculty of Medicine, Charles University, Prague, Czech Republic, ${ }^{8}$ Dept. of Pathophysiology, Second Faculty of Medicine, Charles University, Prague, Czech Republic

Received June 2, 2021

Accepted August 26, 2021

Epub Ahead of Print October 30, 2021

\begin{abstract}
Summary
Mechanical circulatory support (MCS) with an implantable left ventricular assist device (LVAD) is an established therapeutic option for advanced heart failure. Most of the currently used LVADs generate a continuous stream of blood that decreases arterial pulse pressure. This study investigated whether a change of the pulse pressure during different pump speed settings would affect cerebral autoregulation and thereby affect cerebral blood flow (CBF). The study included 21 haemodynamically stable outpatients with a continuous-flow LVAD (HeartMate II, Abbott, USA) implanted a median of 6 months before the study (interquartile range 3 to 14 months). Arterial blood pressure (measured by finger plethysmography) was recorded simultaneously with CBF (measured by transcranial Doppler ultrasound) during baseline pump speed (8900 rpm [IQR 8800; 9200]) and during minimum and maximum tolerated pump speeds (8000 rpm [IQR 8000; 8200] and 9800 rpm [IQR 9800; 10 000]). An increase in LVAD pump speed by $800 \mathrm{rpm}$ [IQR $800 ; 1000]$ from the baseline lead to a significant decrease in arterial pulse pressure and cerebral blood flow pulsatility (relative change $-24 \%$ and $-32 \%$, both $p<0.01$ ), but it did not affect mean arterial pressure and mean $\mathrm{CBF}$ velocity (relative change $1 \%$ and $-1.7 \%, p=0.1$ and 0.7$)$. In stable patients with a continuous-flow LVAD, changes of pump speed settings within
\end{abstract}

a clinically used range did not impair static cerebral autoregulation and cerebral blood flow.

\section{Key words}

LVAD - Continuous flow - Plethysmography - Cerebral autoregulation

\section{Corresponding author}

Ondrej Szárszoi, Department of Cardiac Surgery, Institute for Clinical and Experimental Medicine, Vídeňská 1958/9, 14021 Prague, Czech Republic. Email: onsz@ikem.cz

\section{Introduction}

Heart failure is one of the major causes of morbidity and mortality, with an increasing prevalence of 1-2\%, burdened by an unfavorable 5-year mortality of 45-60 \% (Pirk et al. 2019). Available therapeutic options for refractory heart failure are heart transplantation or mechanical circulatory support (MCS) implantation. MCSs have been broadly adopted as a treatment based on excellent survival rates and reasonable rates of adverse events, both of which are linked to the rapid evolution of these devices in recent years. Almost $95 \%$ of todays' 
long-term MCS systems generate non-pulsatile, i.e., continuous flow (Kirklin et al. 2017), challenging the physiological paradigm of pulsatility being indispensable for proper end-organ function, including cerebral autoregulation.

Cerebral autoregulation is a crucial mechanism for managing the delivery of oxygenated blood to the brain in response to blood pressure variations. This complex regulatory mechanism consists of the following determinants of cerebral blood flow (CBF): (a) metabolic autoregulation, which is sensitive to changes in arterial PO2 and PCO2, (b) myogenic autoregulation, which alters arterial diameter, i.e., changes vascular resistance in response to blood pressure changes, (c) matches local blood flow to localized metabolic needs, and (d) facilitates the need to extract large amounts of the available oxygen (Kittnar et al. 2011, Willie et al. 2011).

Changes in cerebral circulation can occur perioperatively during left ventricular assist device (LVAD) implantation (e.g., ischemia or subsequent microembolisation) or shortly after LVAD implantation (e.g., cerebral hyperperfusion syndrome after long periods of tissue hypoperfusion). Later on, changes in cerebral circulation can be caused by disruption of the baroreflex or the failure of cerebrovascular regulatory mechanisms (Cornwell et al. 2015).

The arterial pulse pressure is thought to be an important determinant of cerebral autoregulation. The rate of pulsatility in continuous-flow left ventricular assist devices (CF-LVAD) closely correlates with pump speed settings, i.e., the higher the pump speed, the lower the observed pulsatility. Nevertheless, there is still a residual, although non-physiological, pulse pressure regardless of flow rate (Cornwell et al. 2015). Published data suggest that CF-LVAD patients are exposed to low-oscillatory blood flows, which negatively affects physiological hemodynamics. Thus, indicating that a modest increase in arterial pulsatility to preserve cerebral autoregulation, i.e., to maintain normal brain physiology, may be beneficial (Stöhr et al. 2019).

Therefore, our study aimed to investigate the effect of different LVAD pump speed settings on cerebral perfusion, especially high-speed settings, which are characterized by the greatest suppression of pulsatility.

\section{Methods}

The study was approved by the Institutional Ethics Committee, and all patients signed informed consent. The study population comprised 21 haemodynamically stable outpatients with an implanted continuous-flow LVAD (HeartMate II, Abbott, USA). All patients had international normalized ratios (INR) within the therapeutic range (1.8-3.0) maintained by warfarin.

The experiment was performed with patients in a supine position, in a quiet, darkened room, after a resting period of at least 10 minutes. Arterial blood pressure was measured continuously using finger plethysmography (Finometer ${ }^{\mathrm{TM}}$, Finapres Medical Systems, Amsterdam, The Netherlands). Cerebral blood flow in both middle cerebral arteries was measured
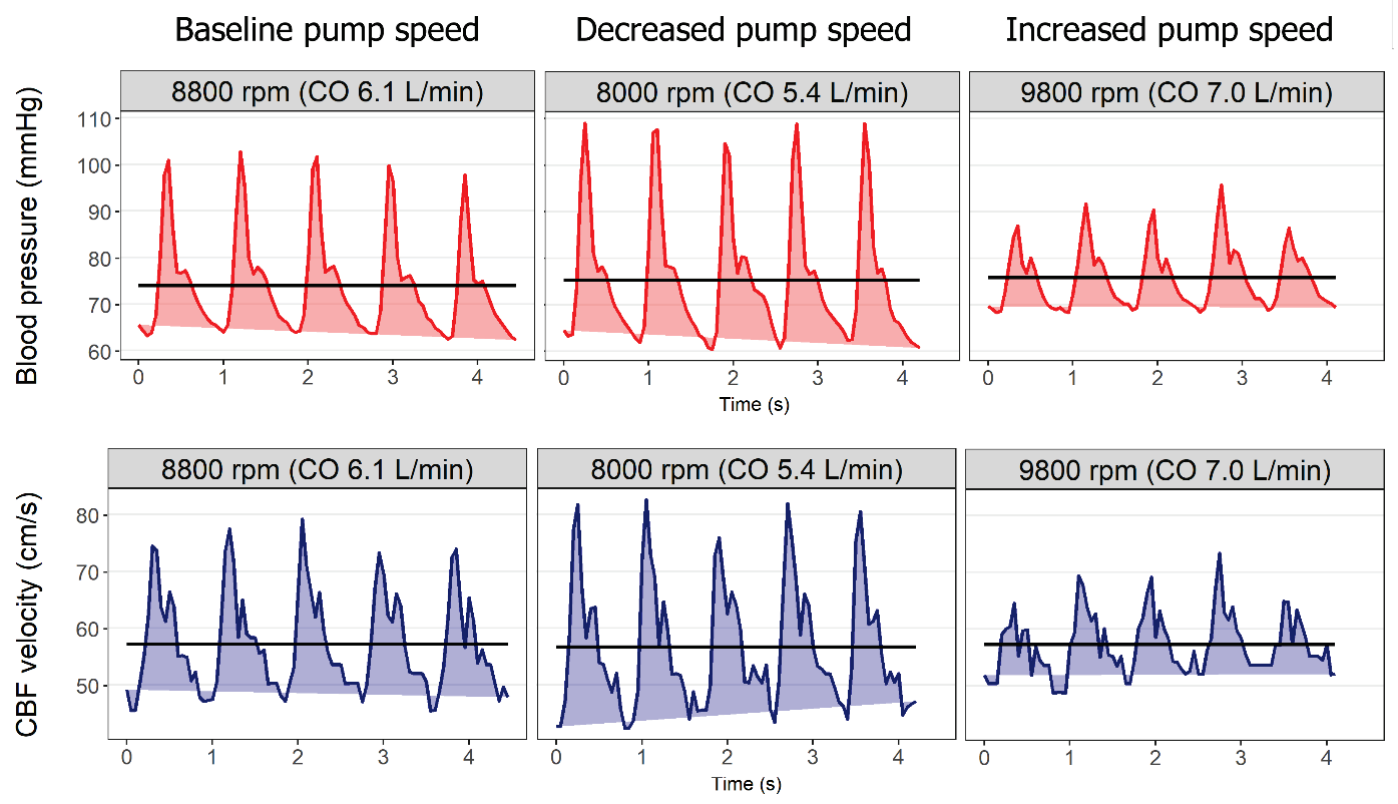

Fig. 1. An example of hemodynamic data measured during different pump speed. $\mathrm{CBF}=$ cerebral blood flow; $\mathrm{CO}=$ pump flow. 
continuously using transcranial Doppler ultrasound fixed to the temples (Rimed Rigi-Lite TM version 16, Rimed Ltd., Ra'anana, Israel). All signals were simultaneously recorded at $1 \mathrm{kHz}$ by a data acquisition system (PowerLab 16/35, ADInstruments, Sydney, Australia). The first recording was obtained at the default pump speed (i.e., baseline; $8900 \mathrm{rpm}$ [IQR 8800; 9200]). A second recording was obtained for pump speeds that were decreased by $-800 \mathrm{rpm}$ [IQR $800 ; 1000$ ] from baseline (MIN; $8000 \mathrm{rpm}$ [IQR 8000; 8200]), all while taking into consideration the patient's hemodynamic tolerance. A third recording was obtained for pump speeds increased by $800 \mathrm{rpm}$ [IQR 800; 1000] above baseline (MAX; $9800 \mathrm{rpm}$ [IQR 9800; 10 000]) while avoiding suction of the emptied left ventricle by the LVAD inflow cannula. Each recording was 2 minutes long. Each recording was preceded by a 2-minute stabilisation period. An example of the recorded blood pressure and CBF signals at different pump speed settings is shown in Figure 1.

The recorded signals were processed offline using a dedicated software package (LabChart 7, ADInstruments). Analyzed parameters included beat-bybeat mean arterial pressure (MAP), arterial pulse pressure, mean $\mathrm{CBF}$ velocity, CBF pulsatility (maximum-minimum $\mathrm{CBF}$ velocity), and heart rate. MAP and $\mathrm{CBF}$ were obtained from the electronic mean of the signal curves. Pump flow, expressed in $1 / \mathrm{min}$, was estimated by the LVAD control console (software algorithm based on actual electrical power consumption and pump speed). For each 2-minute segment, the beat-by-beat values were averaged to a single value. Values of CBF and CBF pulsatility from both cerebral arteries were averaged.

Statistical analyses were performed in R 3.4 (R-project.org, Vienna, Austria). Continuous normally distributed variables are expressed as mean \pm standard deviation, non-normally distributed variables as median and interquartile range. The significance of hemodynamic changes for the three pump speed settings was analyzed using one-way ANOVA. Comparisons of hemodynamic parameters between any two different pump speed settings were analyzed using a paired t-test. Group comparisons were performed using the Student's t-test, chi-square test, and the Fisher's test, as appropriate. Correlations among continuous variables were analyzed using Pearson's test. A p-value $<0.05$ was considered statistically significant. A non-significant change of mean $\mathrm{CBF}$ velocity after a significant change of the pump flow was considered a sign of preserved static cerebral autoregulation.

\section{Results}

The study protocol was completed in all 21 patients. The patients' clinical characteristics are summarised in Table 1; the measured hemodynamic parameters are summarised in Table 2 . The average patient age was $47 \pm 13$ years, and 19 patients (91\%) were males. The median time on the LVAD support at the time of the study was 167 days [IQR 81; 411]. Although one-third of the patients had a history of atrial fibrillation, all of them were in sinus rhythm at the time of the study. Eight patients $(38 \%)$ had a previous history of a cerebrovascular accident (TIA, $\mathrm{n}=3$; stroke, $\mathrm{n}=5$ ). All patients were on chronic therapy with beta-blockers. At baseline, the pump speed was set to $8900 \mathrm{rpm}$ [IQR 8800; 9200], which generated a pump flow of $4.1 \pm 0.8 \mathrm{~L} / \mathrm{min}$ (Table 2). A decrease in the pump speed from baseline by $800 \mathrm{rpm}$ [IQR 800; 1000] led to a decrease in the pump flow by $-15 \%([\mathrm{IQR}-26 ;-15] ; \mathrm{p}<0.001)$ and a decrease in MAP pressure by $-3.4 \%([\mathrm{IQR}-6.5 ;-1.2] ; \mathrm{p}=0.1)$.

Table 1. Baseline characteristics of the study population

\begin{tabular}{lc}
\hline Characteristic & $\mathbf{2 1 ( 1 0 0 )}$ \\
\hline Male gender & $19(91)$ \\
Mean Age (years) & $47 \pm 13$ \\
Ischemic cardiomyopathy & $8(38)$ \\
Non-ischemic cardiomyopathy & $13(62)$ \\
Duration of heart failure, days & $599[393 ; 2049]$ \\
History of atrial fibrillation & $7(33)$ \\
Transient ischemic attack or & $8(38)$ \\
stroke & $5(24)$ \\
Stroke & $3(14)$ \\
Transient ischemic attack & $0(0 \%)$ \\
Stenosis of carotid artery $>70 \%$ & $5(24)$ \\
Arterial hypertension & $4(19)$ \\
Diabetes mellitus & $13(62)$ \\
Smoking history & $20(95)$ \\
LVAD as a bridge to & $1(5)$ \\
transplantation & $167[81 ; 411]$ \\
LVAD as a destination therapy & $21(100)$ \\
Time on LVAD, days & $17(81)$ \\
Beta-blockers & \\
ACEI/ARB &
\end{tabular}

The values are mean \pm standard deviation, median [inter-quartile range] and frequency (percentage). ACEI/ARB=angiotensinconverting enzyme inhibitor/angiotensin receptor blocker; LVAD=left ventricular assist device. 
Table 2. Hemodynamics at the different pump speed settings

\begin{tabular}{|c|c|c|c|c|c|c|}
\hline \multirow[t]{2}{*}{ Variable } & \multirow{2}{*}{$\begin{array}{r}\text { Baseline } \\
\text { setting }\end{array}$} & \multirow{2}{*}{$\begin{array}{c}\text { Min } \\
\text { (decreased } \\
\text { pump speed) }\end{array}$} & \multirow{2}{*}{$\begin{array}{c}\text { Max } \\
\text { (increased } \\
\text { pump speed) }\end{array}$} & \multicolumn{3}{|c|}{ P-value } \\
\hline & & & & $\begin{array}{l}\text { Baseline } \\
\text { vs. Min }\end{array}$ & $\begin{array}{l}\text { Max vs. } \\
\text { baseline }\end{array}$ & $\begin{array}{l}\text { Max vs. } \\
\text { Min }\end{array}$ \\
\hline $\begin{array}{l}\text { Pump speed, } \\
\text { revolutions/min }\end{array}$ & $8929 \pm 222$ & $8048 \pm 108$ & $9819 \pm 244$ & $<0.001$ & $<0.001$ & $<0.001$ \\
\hline Pump flow, l/min & $5.1 \pm 0.8$ & $4.1 \pm 0.8$ & $6.0 \pm 0.9$ & $<0.001$ & $<0.001$ & $<0.001$ \\
\hline Heart rate, beats/min & $76 \pm 15$ & $78 \pm 15$ & $76 \pm 16$ & 0.3 & 0.2 & 0.5 \\
\hline $\begin{array}{l}\text { Mean arterial } \\
\text { pressure, } \mathrm{mmHg}\end{array}$ & $98 \pm 15$ & $94 \pm 15$ & $99 \pm 16$ & $<0.001$ & 0.1 & $<0.001$ \\
\hline $\begin{array}{l}\text { Arterial pulse } \\
\text { pressure, } \mathrm{mmHg}\end{array}$ & $18 \pm 80$ & $22 \pm 10$ & $13 \pm 60$ & $<0.001$ & $<0.001$ & $<0.001$ \\
\hline Mean $C B F, \mathrm{~cm} / \mathrm{s}$ & $71 \pm 16$ & $67 \pm 16$ & $74 \pm 18$ & $<0.01$ & 0.7 & $<0.001$ \\
\hline CBF pulsatility, $\mathrm{cm} / \mathrm{s}$ & $23 \pm 11$ & $32 \pm 15$ & $18 \pm 9$ & $<0.001$ & $<0.001$ & $<0.001$ \\
\hline
\end{tabular}

The $\mathrm{p}$-values were obtained by paired $\mathrm{t}$-test. $\mathrm{CBF}=$ cerebral blood flow

Table 3. Hemodynamics according to the history of a previous cerebrovascular accident

\begin{tabular}{|c|c|c|c|}
\hline & $\begin{array}{l}\text { No history of CVA } \\
\qquad(n=13)\end{array}$ & $\begin{array}{l}\text { History of CVA* } \\
\qquad(n=8)\end{array}$ & P-value \\
\hline \multicolumn{4}{|c|}{ Baseline pump speed (8900 rpm [IQR 8800; 9200]) } \\
\hline Heart rate, beats/min & $82 \pm 16$ & $73 \pm 13$ & 0.2 \\
\hline Pump flow, l/min & $5.1 \pm 0.7$ & $5.2 \pm 0.9$ & 0.8 \\
\hline Mean arterial pressure, $\mathrm{mmHg}$ & $99 \pm 18$ & $95 \pm 16$ & 0.6 \\
\hline Arterial pulse pressure, $\mathrm{mmHg}$ & $16 \pm 9$ & $21 \pm 6$ & 0.2 \\
\hline Mean $C B F, \mathrm{~cm} / \mathrm{s}$ & $60 \pm 10$ & $69 \pm 22$ & 0.3 \\
\hline$C B F$ pulsatility, $\mathrm{cm} / \mathrm{s}$ & $22 \pm 10$ & $27 \pm 13$ & 0.4 \\
\hline \multicolumn{4}{|c|}{ Minimal pump speed (8000 rpm [IQR 8000; 8200]) } \\
\hline Heart rate, beats/min & $83 \pm 16$ & $72 \pm 12$ & 0.1 \\
\hline Pump flow, l/min & $4.0 \pm 0.9$ & $4.3 \pm 0.6$ & 0.5 \\
\hline Mean arterial pressure, $\mathrm{mmHg}$ & $96 \pm 17$ & $90 \pm 14$ & 0.4 \\
\hline Arterial pulse pressure, $\mathrm{mmHg}$ & $21 \pm 12$ & $26 \pm 5$ & 0.2 \\
\hline Mean $C B F, \mathrm{~cm} / \mathrm{s}$ & $57 \pm 8$ & $66 \pm 20$ & 0.3 \\
\hline CBF pulsatility, $\mathrm{cm} / \mathrm{s}$ & $30 \pm 13$ & $35 \pm 15$ & 0.5 \\
\hline \multicolumn{4}{|c|}{ Maximal pump speed (9800 rpm [IQR 9800; 10 000]) } \\
\hline Heart rate, beats $/ \mathrm{min}$ & $80 \pm 17$ & $70 \pm 12$ & 0.1 \\
\hline Pump flow, l/min & $6.0 \pm 0.9$ & $5.9 \pm 1.1$ & 0.8 \\
\hline Mean arterial pressure, $\mathrm{mmHg}$ & $101 \pm 18$ & $97 \pm 16$ & 0.7 \\
\hline Arterial pulse pressure, $\mathrm{mmHg}$ & $11 \pm 5$ & $14 \pm 4$ & 0.09 \\
\hline Mean $C B F, \mathrm{~cm} / \mathrm{s}$ & $62 \pm 10$ & $68 \pm 20$ & 0.5 \\
\hline$C B F$ pulsatility, $\mathrm{cm} / \mathrm{s}$ & $14 \pm 5$ & $20 \pm 12$ & 0.2 \\
\hline
\end{tabular}

$\mathrm{CBF}=$ cerebral blood flow; $\mathrm{CVA}=$ cerebrovascular accident; The table shows no significant differences in the systemic hemodynamics and cerebral blood flow in patients with a history of CVA (transient ischemic attack, $n=3$; stroke, $n=5$ ) compared to the rest of the study population.

As a result of the greater contribution of the native left ventricular contractions, the pump flow decrease was accompanied by a significant increase in arterial pulse pressure by $19 \%$ ([IQR 10; 40]; p < 0.001) and CBF pulsatility by $31 \%$ ([IQR 21; 50]; p < 0.001) (Table 2).

However, the decrease in MAP led to systemic 
hypoperfusion with a decrease in the mean CBF velocity by $-8 \%([\mathrm{IQR}-11 ;-1.6] ; \mathrm{p}<0.01)$ (Table 2$)$.

An increase in pump speed by $800 \mathrm{rpm}$ [IQR 800; 1000] above baseline caused an increase in pump flow by $15 \%$ ([IQR $11 ; 22]$; p < 0.001), a decrease in arterial pulse pressure by $-24 \%$ ([IQR $-29 ;-13]$; $\mathrm{p}<0.001$ ), and a decrease in CBF pulsatility by $-18 \%$ ([IQR $-34 ;-6] ; \mathrm{p}<0.001)$, but it did not affect the MAP or the mean CBF velocity (Table 2).

There was a strong correlation only between CBF pulsatility and pump flow and arterial pulse pressure but not between the mean CBF velocity and pump flow and arterial pulse pressure (Fig. 2).

Based on the analysis of variance, pump speed settings were only associated with changes in pump flow, arterial pulse pressure, and CBF pulsatility but were not associated with significant changes in HR, MAP, or mean CBF velocity (Fig. 3).

\section{Discussion}

This study investigated the acute effect of different LVAD pump speed settings on static cerebral autoregulation. An important finding was that even at the maximum tolerated pump speed, measurable arterial pulsatility, and CBF pulsatility remained. Additionally, the study found that CBF did not change significantly at the increased pump speeds. The latter finding suggests that within the clinically feasible range of pump speed settings, experimental changes in blood flow do not affect static cerebral autoregulation and $\mathrm{CBF}$, despite significant changes in arterial pressure pulsatility.
CBF vs. arterial pulse pressure

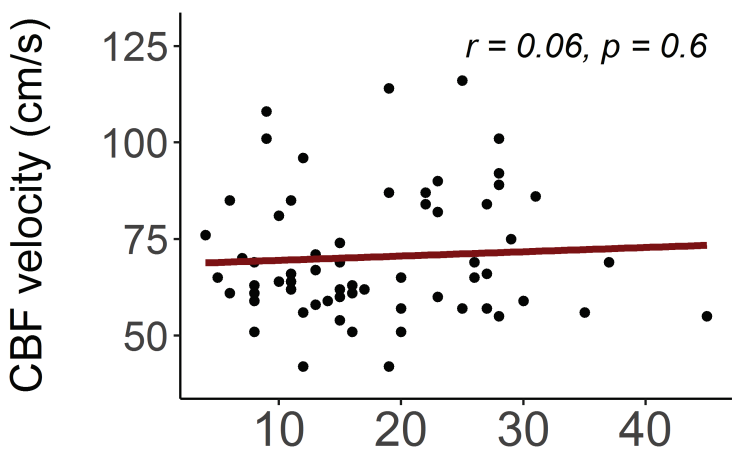

Arterial pulse pressure $(\mathrm{mmHg})$

CBF pulsatility vs. arterial pulse pressure

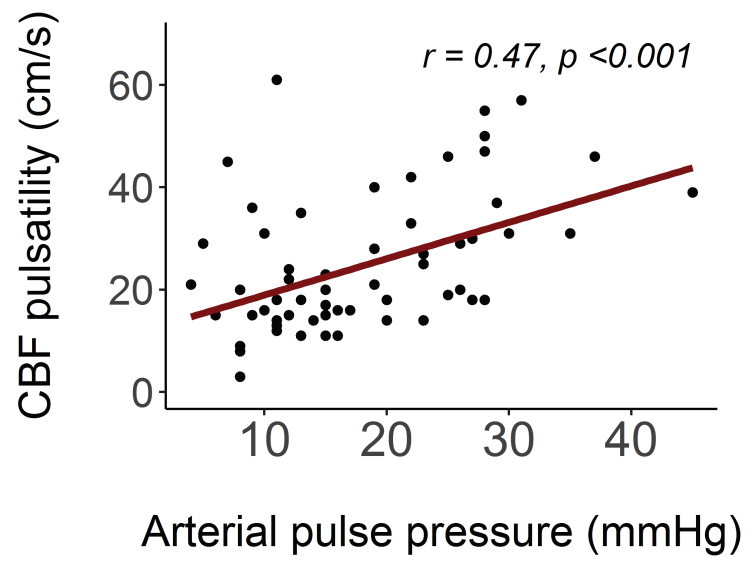

CBF vs. pump flow

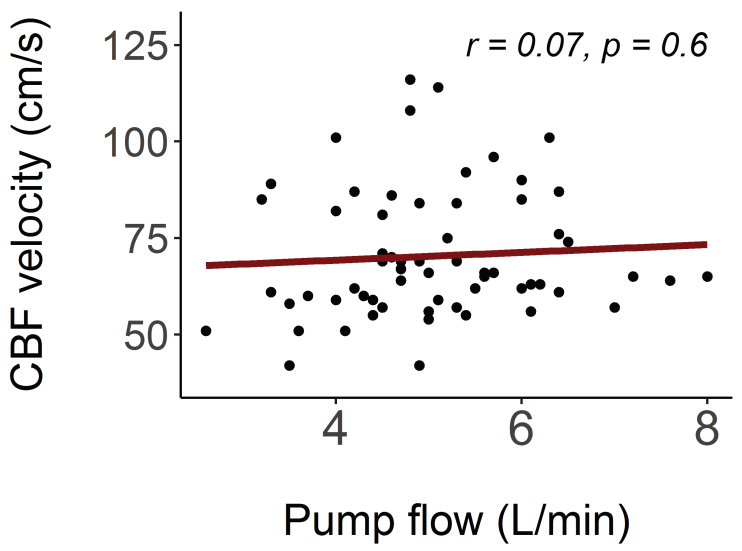

CBF pulsatility vs. pump flow

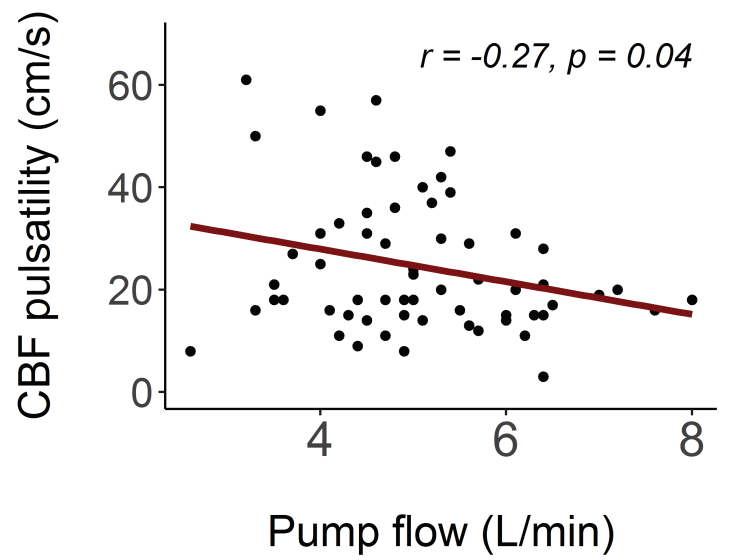

Fig. 2. Correlation between mean cerebral blood flow velocity and pulsatility relative to pump flow and arterial pulse pressure. $\mathrm{CBF}=$ cerebral blood flow. The datapoints were pooled from all continuous-flow left ventricular assist device patients at the three different pump speeds (MIN=8000 rpm [IQR 8000; 8200]; baseline $=8900 \mathrm{rpm}$ [8800; 9200]; MAX=9800 rpm [9800; 10 000]). The graphs show constant mean cerebral blood flow velocity despite variable arterial pulse pressure and pump speed, pump flow respectively. 

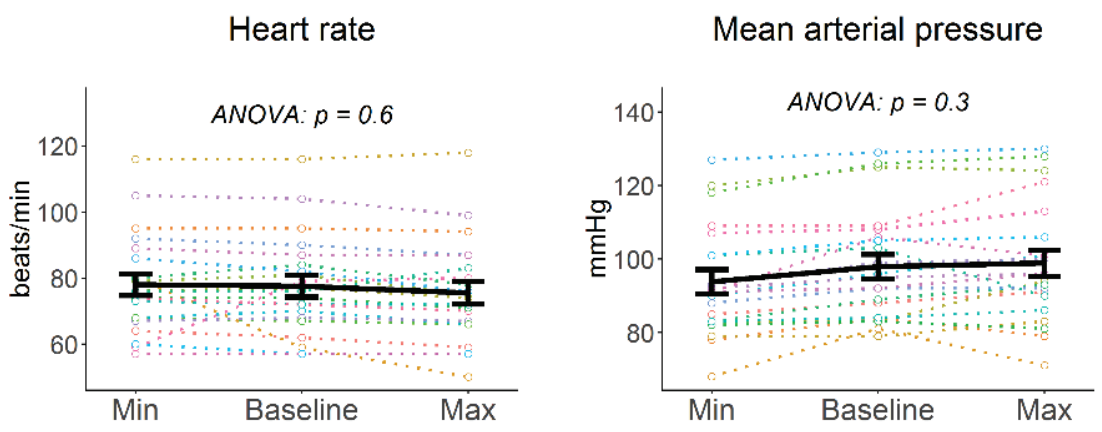

Pump flow

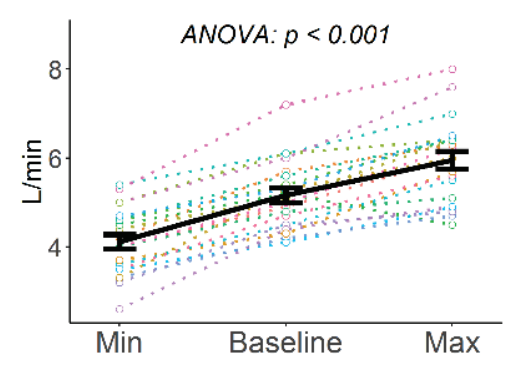

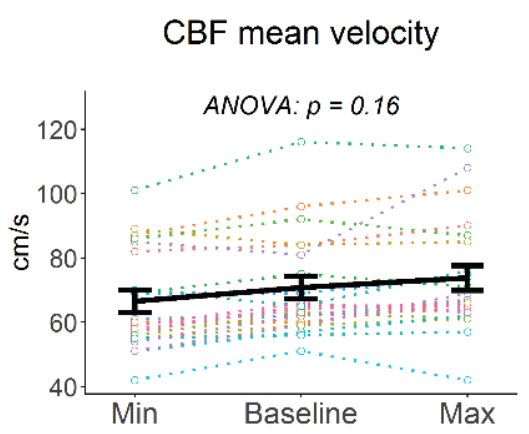

Arterial pulse pressure
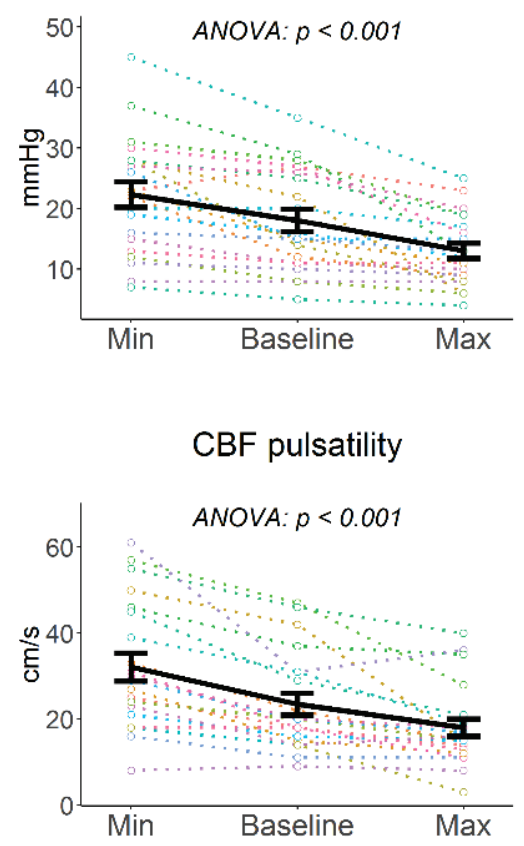

Fig. 3. Systemic Hemodynamics and cerebral blood flow at different pump speeds. $C B F=$ cerebral blood flow. The graphs show the change in the hemodynamic parameters at different pump speeds. The colored dotted lines represent data from each patient. The thick black lines represent the average values with the standard error.

CF-LVADs represent the majority of long-term MCS implants in the current era (Kirklin et al. 2017). Although CF-LVADs have several advantages over pulsatile devices, controversy remains over the effects of CF-LVADs on end-organ function due to the reduction in pulsatility, particularly as it relates to cerebral perfusion and autoregulation (Ono et al. 2012). There are few published papers concerning cerebral autoregulation in CF-LVAD patients; however, unambiguous conclusions are missing. Katherine Lietz et al. described for the first time in 2009, the relationship between LVAD high speeds, i.e., high pump flow, and the increased occurrence of neurologic dysfunction in the early postimplant period. The reported prevalence reached $27 \%$ of LVAD implanted patients in the first 30 days. In $87 \%$ of affected patients, the neurologic deficit was transient and reversed after reducing LVAD flow. The authors of this article suggested that this was due to the sudden hyperperfusion, after LVAD implantation, of long-term hypoperfused cerebral tissue, which is typical with chronic heart failure. Cerebral autoregulatory mechanisms cannot adequately correct for a precipitous increase in cardiac output (Lietz et al. 2009).

Another study dealing with cerebrovascular dysregulation in LVAD patients was conducted by Judith Bellapart et al. However, a definite conclusion concerning the possible failure of cerebrovascular regulation was not reached even though the authors of the study were leaning towards some degree of dysregulation. The study's main limitations were the low number of study subjects $(n=5)$ and the use of pulsatile devices (Bellapart et al. 2011). On the other hand, Masahiro Ono et al. reported preserved cerebrovascular regulation in a cohort of 15 patients implanted with CF-LVADs (Ono et al. 2012). However, the patients were only followed during the early post-implant period, which limits long-term conclusions. A recent study by Cornwell et al. investigated 14 LVAD patients (9 of whom had CF-LVADs) and compared them to ten healthy controls. The authors also assessed the dynamic part of cerebral autoregulation. They found that cerebral blood flow was comparable, suggesting that the reduction in pulsatility associated with CF-LVADs does not impair normal autoregulatory processes (Cornwell et al. 2014).

Impaired cerebral autoregulation goes hand in hand with adverse neurological outcomes (Bellapart et al. 2011, Bozkurt 2018, Caldas et al. 2018, Lietz et al. 2009, Pham et al. 2015). However, things other than malfunctions of the autoregulatory processes can be responsible for neurological deficits in CF-LVAD patients. There are several views on this topic, with most of them emphasizing, to some degree, the importance of 
altered pulsatility. Impairment of microcirculation oxygen kinetics due to low pulsatile, diastolic-dominant Hemodynamics was postulated by Stöhr et al. (Stöhr et al. 2019). On the other hand, Cornwell et al. found adverse neurologic events to be a consequence of other LVAD-related complications, such as gastrointestinal bleeding, pump thrombosis, infection, and atrial fibrillation (Cornwell et al. 2019), which diminished the influence of lower pulse pressures.

Of note, eight patients (38\%) had a previous history of a cerebrovascular accident, but none of them had any apparent residual neurological symptoms at the time of the study. There was also no difference in the hemodynamics between the patients with previous cerebrovascular history and the rest of the patients (Table 3).

Since improvements in the morbidity and mortality of LVAD-implanted patients are always warranted, more studies on this topic need to be conducted. We focused on the possible effect of variable LVAD pump speed settings on neurological disturbances because of its potential to impair cerebral autoregulation. Our findings should be of great interest to clinicians since the optimization of LVAD pump speed settings is crucial for implanted patients. Adequate unloading of the failing ventricle accompanied by loss of native contractility results in a substantial loss of pulsatility in LVADimplanted patients, potentially leading to cerebral autoregulation disturbances.

Optimal pump speed settings should lead to sufficient unloading of the ventricle and enable the intermittent opening of the aortic valve to prevent blood stasis and provide adequate cardiac output. Maintaining the patient's INR within the therapeutic range is a precondition for any change in pump speed. In our department, echocardiographic guidance is routinely used to optimize LVAD parameters so that patients are discharged in an optimized hemodynamic condition. The optimised LVAD settings described above represent the baseline condition of the patients in our study.

In our study, LVAD pump speeds were reduced to accentuate the residual contractility of the dysfunctional ventricle, thus increasing systolic-diastolic differences. Increasing the pulsatile element of blood pressure mimics physiological conditions, i.e., there is no cerebral autoregulation impairment, which is the expected finding. Conversely, increasing LVAD revolutions per minute (rpm) simulated total loss of pulsatility. This adjustment of LVAD settings led to a substantial increase in blood flow, while the mean arterial pressure and mean CBF velocity remained stable. In our opinion, the constancy of these particular parameters leads to the preservation of cerebral vascular resistance. In other words, stable mean $\mathrm{CBF}$ velocity maintains adequate tension variability in vascular smooth muscle cells in response to intraluminal pressure changes.

It is noteworthy that even at maximally tolerated pump speeds, the average pulse pressure was still around $13 \mathrm{mmHg}$. This phenomenon has been well-described in previously published papers and is often referred to as a non-physiological pulse (i.e., approx. $20 \mathrm{mmHg}$ ) (Cornwell et al. 2015). It results from the left ventricle ejecting blood through the LVAD pathway (Pagani 2008). It results from fluctuations in the intra-ventricular pressures during each cardiac cycle (Pham et al. 2015). Regardless of LVAD pump speeds, the permanent presence of residual pulsatility in CF-LVAD patients might be beneficial in the sense of a reduction in adverse events (Stöhr et al. 2019).

Our findings from a relatively large group of patients with continuous-flow LVAD suggest that static cerebral autoregulation is preserved when pulsatility is experimentally reduced. Additionally, LVAD pump speed optimization is a routine and safe procedure performed during the post-implant period and is not associated with neurological disturbances.

\section{Limitations}

Due to safety considerations, the study evaluated only the static component of cerebral autoregulation. Evaluation of dynamic autoregulation would require periodic manipulation of blood pressure using manoeuvres such as synchronized deep breathing. However, sudden changes in blood pressure in LVAD patients often lead to suction events with an increased risk of ventricular arrhythmias. Furthermore, it should be highlighted that the study evaluated only acute hemodynamic changes in otherwise stable LVAD patients. Long-term manipulation via pump speed settings would impose an unacceptable risk of hemodynamic decompensation or symptomatic suction events. The majority of patients were young males with non-ischemic etiologies of chronic heart failure and more likely to have intact reflexes such as cerebral autoregulation than elderly patients or patients with ischemic chronic heart failure. This study primarily reflects male physiology since women were only $9 \%$ of the cohort. A major part of the patients in our study cohort were using 
beta-blockers, angiotensin-converting enzyme inhibitors, or angiotensin-receptor blocker antagonists at the time of the study. The possible influence of these medications on study results cannot be ruled out.

\section{Conflict of Interest}

There is no conflict of interest.

\section{References}

BELLAPART J, CHAN GC, TZENG YC, AINSLIE P, BARNETT AG, DUNSTER KR, BOOTS R, FRASER JF: The effect of ventricular assist devices on cerebral autoregulation: a preliminary study. BMC Anesthesiol 11: 1-8, 2011. https://doi.org/10.1186/1471-2253-11-4

BOZKURT S: Effect of cerebral flow autoregulation function on cerebral flow rate under continuous flow left ventricular assist device support. Artif Organs 42: 800-813, 2018. https://doi.org/10.1111/aor.13148

CALDAS JR, HAUNTON VJ, PANERAI RB, HAJJAR LA, ROBINSON TG: Cerebral autoregulation in cardiopulmonary bypass surgery: a systematic review. Interact Cardiovasc Thorac Surg 26: 494-503, 2018. https://doi.org/10.1093/icvts/ivx357

CORNWELL WK 3rd, TARUMI T, AENGEVAEREN VL, AYERS C, DIVANJI P, FU Q, PALMER D, DRAZNER MH, MEYER DM, BETHEA BT, HASTINGS JL, FUJIMOTO N, SHIBATA S, ZHANG R, MARKHAM DW, LEVINE BD: Effect of pulsatile and nonpulsatile flow on cerebral perfusion in patients with left ventricular assist devices. J Heart Lung Transplant 33: 1295-1303, 2014. https://doi.org/10.1016/j.healun.2014.08.013

CORNWELL WK 3rd, TARUMI T, STICKFORD A, LAWLEY J, ROBERTS M, PARKER R., FITZSIMMONS C, KIBE J, AYERS C, MARKHAM D, DRAZNER MH, FU Q, LEVINE BD: Restoration of pulsatile flow reduces flow sympathetic nerve activity among individuals with continuous-flow left ventricular assist devices. Circulation 132: 2316-2322, 2015. https://doi.org/10.1161/CIRCULATIONAHA.115.017647

CORNWELL WK 3rd, TARUMI T, LAWLEY J, AMBARDEKAR AV: Crosstalk opposing view: Blood flow pulsatility in left ventricular assist device patients is not essential to maintain normal blood physiology. J Physiol 597: 357-359, 2019. https://doi.org/10.1113/JP276730

KIRKLIN JK, PAGANI FD, KORMOS RL, STEVENSON LW, BLUME ED, MYERS SL, MILLER MA, BALDWIN JT, YOUNG JB, NAFTEL DC: Eight annual INTERMACS report: Special focus on framing the impact of adverse events. J Heart Lung Transplant 36: 1080-1086, 2017. https://doi.org/10.1016/j.healun.2017.07.005

KITTNAR O: Medical Physiology. LOMICEK J, Grada, Prague, 2011, pp 241-242.

LIETZ K, BROWN K, ALI SS, COLVIN-ADAMS M, BOYLE AJ, ANDERSON D, WEINBERG AD, MILLER LW, PARK S, JOHN R, LAZAR RM: The role of cerebral hyperperfusion in postoperative neurologic dysfunction after left ventricular assist device implantation for end-stage heart failure. J Thorac Cardiovascular Surg 137: 1012-1019, 2009. https://doi.org/10.1016/j.jtcvs.2008.11.034

ONO M, JOSHI B, BRADY K, EASLEY RB, KIBLER K, CONTE J, SHAH A, RUSSELL SD, HOGUE CW: Cerebral blood flow autoregulation is preserved after continuous-flow left ventricular assist device implantation. J Cardiothorac Vasc Anesth 26:1022-1028, 2012. https://doi.org/10.1053/j.jvca.2012.07.014

PAGANI FD: Continuous-flow rotary left ventricular assist devices with "3rd generation" design. Semin Thorac Cardiovasc Surg 20: 255-263, 2008. https://doi.org/10.1053/j.semtcvs.2008.08.002

PHAM P, BINDRA J, CHUAN A, JAEGER M., ANEMAN A: Are changes in cerebrovascular autoregulation following cardiac arrest associated with neurological outcome? Results of a pilot study. Resuscitation 96: 192-198, 2015. https://doi.org/10.1016/j.resuscitation.2015.08.007

PIRK J: Cardiac surgery (in Czech). SPICKOVA M, KRATOCHVILOVA I, PATKOVA V (Eds.), Maxdorf, Prague, 2019, pp 192-193.

STÖHR EJ, MCDONNELL BJ, COLOMBO PC, WILLEY JZ: Crosstalk proposal: Blood flow pulsatility in left ventricular assist device patients is essential to maintain normal brain physiology. J Physiol 597: 353-356, 2019. https://doi.org/10.1113/JP276729 
WILLIE CK, COLINO FL, BAILEY DM, TZENG YC, BINSTED G, JONES LW, HAYKOWSKY MJ, BELLAPART J, OGOH S, SMITH KJ, SMIRL JD, DAY TA, LUCAS SJ, ELLER LK, AINSLIE PN: Utility of transcranial doppler ultrasound for the integrative assessment of cerebrovascular function. J Neurosci Methods 196: 221-237, 2011. https://doi.org/10.1016/j.jneumeth.2011.01.011 